\title{
ПРОЕКТ МОДЕЛИ ВЫЯВЛЕНИЯ СУБЪЕКТОВ, ПРИЧАСТНЫХ К ЛЕГАЛИЗАЦИИ ПРЕСТУПНЫХ ДОХОДОВ
}

\author{
(c) 2021 Сысоев Филипп Игоревич \\ Кафедра теории кредита и финансового менеджмента, магистрант \\ Санкт-Петербургский государственный университет, Россия, Санкт-Петербург \\ E-mail: philipp.sysoev@mail.ru \\ (c) 2021 Константинов Илья Алексеевич \\ Кафедра коммерческого права, магистрант \\ Санкт-Петербургский государственный университет, Россия, Санкт-Петербург \\ E-mail: ilyakonstant1nov@yandex.ru
}

В данной статье была поставлена следующая задача: предложить статистические процедуры, посредством которых можно предположительно определить организации, причастные к отмыванию преступных доходов. Для подобных целей современная наука об анализе данных может предоставить целый спектр приёмов и методов. Среди таких методов можно назвать регрессионный анализ, деревья решений, а также нейросетевые методы. Последние, на взгляд авторов, лучше всего подходят для указанной ситуации ввиду того, что именно нейросетевое моделирование позволяет использовать имеющиеся в данных взаимосвязи, которые недоступны прочим методам анализа. На основании материалов административно-судебной практики авторами строится модель, которую возможно использовать для выявления субъектов, причастных к проведению операций, направленных на легализацию преступных доходов. Также в статье приводится список критериев (имеющих преимущественно экономический характер), которые следует принимать во внимание при определении вероятности причастности субъекта к данному виду противозаконной деятельности. Статистическое обоснование выбора данных критериев также дано в работе.

Ключевые слова: отмывание преступных доходов, Центральный Банк, правила внутреннего контроля, финансовый мониторинг, сомнительные операции

Кредитно-финансовые институты обладают колоссальной значимостью для эффективного функционирования экономики в целом. Не подлежит сомнению, что и без того значимая роль данных учреждений будет ещё больше возрастать в будущем - по мере цифровизации и дальнейшего перехода на безналичные расчёты. В этой связи чрезвычайно важно, чтобы банковская система представляла собой отлаженный механизм, действующий в соответствии с рациональными, ясными и детализированными правилами. Таким образом, предстоящие преобразования в законодательном регулировании системы должны быть нацелены на то, чтобы:

1) Минимизировать возможные негативные последствия для добросовестных хозяйствующих субъектов при реализации кредитными организациями и публичными органами своих полномочий в рамках антиотмывочного законодательства;

2) Повысить эффективность системы выяв- ления недобросовестных экономических агентов путём внедрения научно обоснованных методов.

Анализ многочисленных подзаконных актов ЦБ РФ позволяет сделать вывод о том, что в настоящее время Банк России многое предпринимает для того, чтобы помочь кредитным организациям в определении субъектов, причастных к легализации преступных доходов. Однако, peкомендации ЦБ РФ в основном нацелены на анализ банковских транзакций. Эти рекомендации, действительно, необходимы, однако, на взгляд авторов, недостаточны. Это наблюдение основывается на том, что основным действующим лицом в экономике выступают именно организации, а движение средств на их счетах - это лишь один из аспектов, который характеризует их деятельность. Именно поэтому окончательно классифицировать конкретную деятельность в качестве отмывочной возможно только исходя из анализа деятельности субъекта, который её со- 
вершает. Иными словами, если имеются основания полагать, что организация не соответствует критериям, предъявляемым к хозяйственной деятельности добросовестного экономического субъекта, то тогда и совершаемые ею действия следует детально анализировать на предмет наличия в них противозаконного умысла.

Цель конструируемой модели заключается 8 том, что она, основываясь на исходных статистических данных (например, данных из финансовой и налоговой отчётности фирм), должна уметь относить каждое конкретное наблюдение (в нашем случае - юридическое лицо) к отдельной группе (например, множеству организаций, замешанных в проведении сомнительных операций, или же фирм, не причастных к ним).

В нашем случае имеется выборка, представленная 101 фирмой (данный список сформирован на основании анализа судебноадминистративной практики), в отношении каждой из которых имеется судебное решение относительно её причастности/непричастности к проведению сомнительных операций (помимо этого, каждое судебное решение из представленной выборки было проанализировано автором на предмет законности и обоснованности). Также в нашем распоряжении имеется большой массив информации, который характеризует каждую из этих фирм. Соответственно, построение модели будет происходить в два этапа.

Во-первых, необходимо определить, какие из имеющихся данных являются предположительно важными для анализа. Алгоритм подбора таких факторов будет приведён ниже.

Далее - после того, как факторы будут подобраны - имеющуюся информацию можно будет загружать в (пустую пока что) модель. При этом имеющаяся выборка (101 фирма) будет разбита на две части. Первая часть будет представлять из себя т.н. тренировочное множество (обычно 80\% выборки), работая с которым, модель будет самостоятельно определять соответствующие веса (это множество можно сравнить с множеством задач, к которым даны ответы). Вторая часть данных будет входить в т.н. тестовое множество - на нём будет осуществлена проверка, насколько хорошо модель научилась классифицировать объекты по группам (т.е. в этом случае модель уже не «знает» заранее верный ответ и использует только те алгоритмы, которые она успела выработать, работая с тренировочным множеством).

\section{Этап первый: подборка релевантных фак-} торов

Для отбора значимых факторов необходимо применить ряд методов, относящихся к сфере анализа данных. На первом этапе основным инструментом будет составление так называемых ассоциативных правил. С точки зрения теории анализа данных ассоциация - это взаимосвязь между разными событиями. Соответственно, когда такая взаимосвязь принимает форму правила \{из события А следует событие В\}, то мы имеем дело с ассоциативным правилом. В контексте данного исследования событие В имеет отчётливый смысл: некая фирма вовлечена в совершение сомнительных операций. Соответственно, перед нами стоит задача обнаружения таких событий А, которые могли бы его обусловить. Составление подобных пар A $\rightarrow$ В и означает формулировку различных ассоциативных правил. Приведем основные статистические показатели, которые были рассчитаны нами при отборе релевантных для модели ассоциативных правил. К таковым показателям относятся: 1) поддержка; 2) достоверность; 3) лифт. Дадим краткие определения:

Поддержкой ассоциативного правила называется относительная частота наблюдений, обладающих неким свойством, относительно общего кол-ва наблюдений (например, 30\% наблюдений обладают свойством В).

Достоверностью ассоциативного правила называется мера точности данного правила - то есть отношение числа наблюдений, содержащих как условие (А), так и следствие (В) к числу наблюдений, содержащих только условие (А) (например, из наблюдений, обладающих свойством А, $40 \%$ обладают также свойством В).

Лифтом ассоциативного правила называется мера, позволяющая определить, насколько значимым является условие (А) для следствия (B). Иными словами, при помощи данного показателя мы можем определить, насколько чаще свойство В встречается среди наблюдений, обладающих свойством А, по сравнению со средней частотой наличия свойства В в выборке. Чтобы фактор можно было считать значимым, значение лифта для него должно быть больше 1.

Далее будет приведена таблица, в которой рассчитаны указанные выше статистические характеристики для ряда признаков, которые могут указывать на противозаконный характер деятельности фирмы (см. табл. 1). 
Таблица 1. Факторы и статистики

\begin{tabular}{|l|l|l|l|l|l|}
\hline \multicolumn{1}{|c|}{ Фактор-свойство } & $\begin{array}{c}\text { Число органи- } \\
\text { заций, облада- } \\
\text { ющих таким } \\
\text { свойством (А) } \\
\text { ций, причастных } \\
\text { к сомительным } \\
\text { операциям, } \\
\text { среди фирм, } \\
\text { обладающих } \\
\text { указанным свой- } \\
\text { ством (А и В) }\end{array}$ & поддержка & достоверность & лифт \\
\hline $\begin{array}{l}\text { Уставной капитал мень- } \\
\text { ше 20 тыс. }\end{array}$ & 49 & 27 & $\begin{array}{l}\text { ч4//101= } \\
0.337\end{array}$ & $27 / 49=0.55$ & 1.632 \\
\hline НдС равен 0 & 27 & 28 & 0.337 & $18 / 27=0.667$ & 1.979 \\
\hline $\begin{array}{l}\text { Заработная плата } \\
\text { сотрудников меньше } \\
\text { средней по группе в 1.25 } \\
\text { раз }\end{array}$ & 43 & 23 & 0.337 & $28 / 43=0.651$ & 1.932 \\
\hline $\begin{array}{l}\text { Принадлежность фирмы } \\
\text { к торговой сфере }\end{array}$ & 59 & 12 & 0.337 & $23 / 59=0.389$ & 1.157 \\
\hline $\begin{array}{l}\text { Отсутствие запасов } \\
\text { (только для торговых } \\
\text { фирм) }\end{array}$ & 12 & 9 & $23 / 59=0.389$ & $12 / 12=1$ & 2.571 \\
\hline $\begin{array}{l}\text { Фирма существует ме- } \\
\text { нее 3-х лет }\end{array}$ & 13 & 19 & 0.337 & $9 / 13=0.692$ & 2.054 \\
\hline $\begin{array}{l}\text { В штате всего один } \\
\text { сотрудник }\end{array}$ & 32 & 0.337 & $19 / 32=0.594$ & 1.763 \\
\hline
\end{tabular}

По приведённым данным можно видеть, что такой критерий, как размер уставного капитала (УК), обладает сравнительно малой значимостью для выявления фирм, занимающихся сомнительной деятельностью. Это связано с тем, на что мы уже указывали выше: более двух третей российских фирм имеют уставной капитал меньше, чем 12 тыс. рублей. Тем не менее значение лифта больше единицы для данного критерия, а значит, в его использовании всё же может быть определённый смысл - особенно если сочетать его с другими критериями.

Относительно торговых фирм интересно заметить, что факт принадлежности фирмы к торговой отрасли не сильно повышает её шансы быть замешанной в сомнительной деятельности (всего на 15\%). Таким образом, огромное число торговых фирм в судебной статистике (больше половины всех дел) связано скорее со структурой нашей экономики (значительным объёмом организаций, связанных с торговлей), нежели с тем, что данная категория деятельности обладает каким-то приоритетом перед другими для проведения сомнительных операций. Что действительно имеет значение - так это наличие у торговых фирм запасов. Анализ показал, что отсутствие таковых у торговых фирм с вероятностью 100\% (само собой, эмпирической) указывает на то, что фирма занимается проведением сомнительных операций. Лифт по данному критерию равен 2,571.

Вместе с этим, хорошо видно, что критерии, связанные с неуплатой НДС и перечислением относительно низких налоговых платежей с зарплаты сотрудников, довольно релевантны для целей выявления фирм, связанных с проведением сомнительных операций. По данным критериям лифт почти равен двум - что значит, что среди подобных организаций число фирм, связанных с сомнительными операциями, в два раза больше, чем в среднем. Это указывает на то, что налоговая информация о предприятии является в высшей мере значимой для целей анализа.

Отдельно следует обратить внимание на то, что для организаций различной отраслевой принадлежности критерии их «нормальности» могут быть различными. Так, если для торговой организации наличие запасов является необходимым признаком её деятельности, то в случае с компанией, занимающейся деятельностью в сфере аренды, рекламы или развлекательной индустрии - это отнюдь не так. Данное обстоятельство сделало необходимым проведение определённого экономического анализа перед включением определённого фактора в модель, чтобы такие характеристики, как наличие/отсутствие запасов, учитывались моделью по-разному - в зависимости от специфики деятельности фирмы. 


\section{Этап второй: построение нейросетевой модели}

Имея набор наблюдений (101 фирма), включающий информацию по интересующим нас характеристикам, рассмотренным в предыдущем параграфе, следует приступить к построению нейросетевой модели, которая позволит классифицировать фирму как потенциально замешанную в проведении сомнительных операций.

Схематично предложенную модель можно описать так: она содержит три слоя нейронов (входной, промежуточный и выходной), т.е. обладает итоговой размерностью $(9,9,1)-$ в первом и втором слое 9 нейронов, в третьем -1 . Графически данная схема приведена далее (см. табл. 2) - вместе с теми факторами, которые были отобраны на предыдущем этапе.

Теперь перейдём к непосредственным результатам построенной модели - с тем, чтобы определить, насколько она точна. Точность предсказаний на тренировочном множестве составила $92 \%$, а на тестовом - 90\%, что является хорошим результатом.

Рассмотрим также, в каких случаях представленная модель совершала ошибки. Иными словами, необходимо определить, что у неё получается лучше: определять фирмы, замешанные в совершении сомнительных операций, или же наоборот - идентифицировать фирмы, не причастные к их проведению. С этой целью приведём две таблицы (см. табл. 3) (для тренировочного и тестового множества).

\section{Таблица 2. Схема нейросетевой модели}

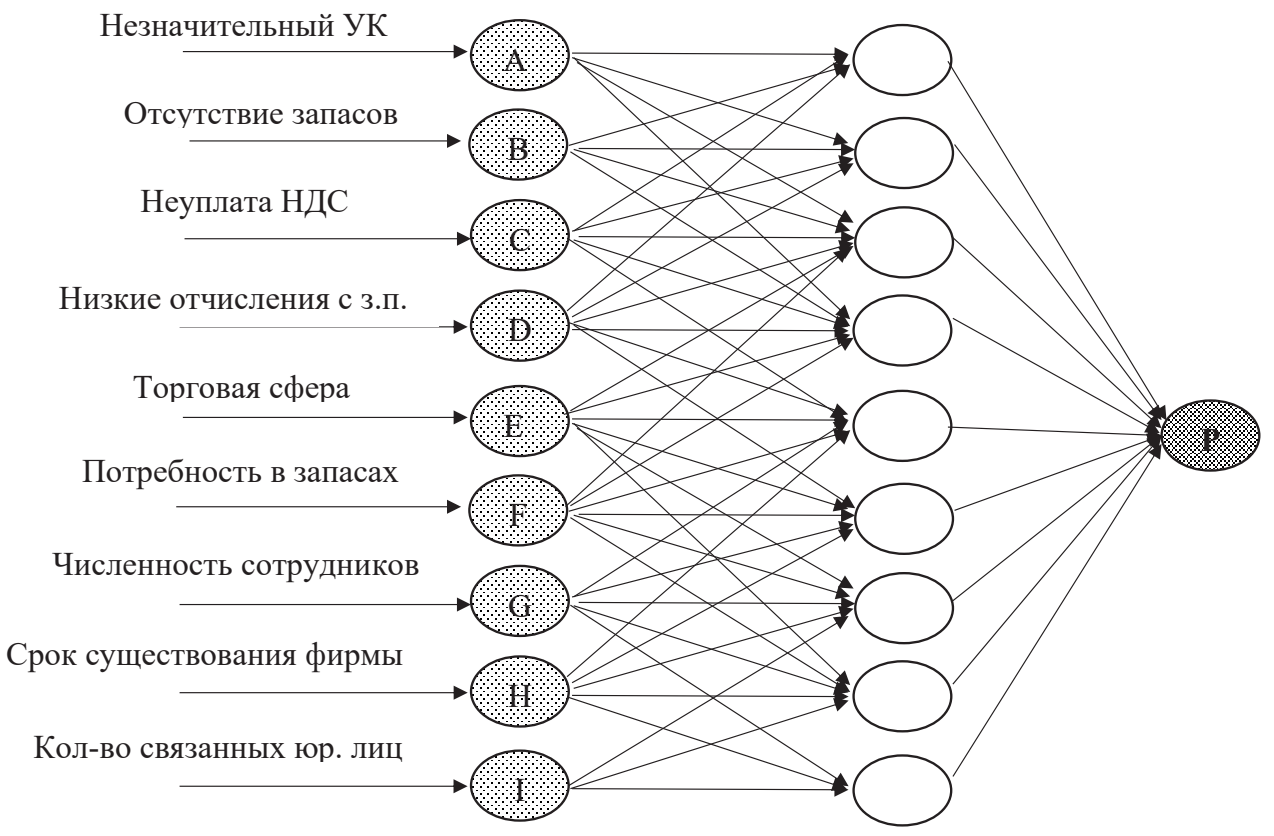

Таблица 3. Тренировочное и тестовое множество

\begin{tabular}{|c|c|c|c|}
\hline \multirow{2}{*}{\multicolumn{2}{|c|}{ Тренировочное множество }} & \multicolumn{2}{|l|}{ В реальности } \\
\hline & & Причастные & Не причастные \\
\hline \multirow{2}{*}{$\begin{array}{l}\text { На основании } \\
\text { предсказаний } \\
\text { модели }\end{array}$} & Причастные & 23050 & 1 \\
\hline & Не причастные & 5 & 51 \\
\hline
\end{tabular}

Тестовое множество

\begin{tabular}{|c|c|}
\hline \multicolumn{2}{|l|}{ В реальности } \\
\hline Причастные & Не причастные \\
\hline 5. & 1 \\
\hline 1 & 14. \\
\hline
\end{tabular}


Штриховкой в приведенных таблицах выделены ячейки, в которых указано число случаев, когда модель давала верные предсказания по сравнению с действительностью. Например, в первой таблице 23 - это число случаев, когда организации, доказанно занимавшиеся проведением сомнительных операций, были классифицированы моделью именно как осуществляющие таковые операции. Напротив, 1 - это количество случаев, когда фирмы, не причастные к противозаконной деятельности, были ошибочно классифицированы моделью как причастные к ней.

В целом, можно видеть, что представленная модель практически не допускает случаев (как на тренировочном, так и на тестовом множестве), когда законопослушная фирма оказывается классифицированной в качестве организации, причастной к проведению сомнительных операций. Таким образом, используемые методы позволяют в разы снизить риск причинения экономического ущерба организациям, не выходящим за рамки законной деятельности. Процент случаев, когда добросовестная оказывается ошибочно идентифицирована как проводящая сомнительные операции, составляют всего $2 \%$ (для тренировочного) и $6 \%$ (для тестового множества).

Теперь рассмотрим точность выявления компаний, занимающихся проведением сомнительных операций. Результаты показывают, что модель верно классифицировала $82 \%$ (для тренировочного) и $83 \%$ (для тестового множества). Это - довольно высокая точность. Тем не менее, определённый процент занимающихся сомнительной деятельностью фирм остаётся неопознанным. Однако, данное обстоятельство не является критическим, поскольку данную модель можно значительно улучшить при обучении на большем количестве примеров и, что важнее - c учётом данных, недоступных на данный момент (например, в совокупности с информацией, до- ступ к которой имеется у банковских сотрудников). Помимо этого, нельзя не принимать во внимание тот факт, что интересы добросовестных экономических агентов (каковыми являются большинство фирм) должны быть приоритетом для лии, ответственных за разработку и проведение экономической политики. Это значит, что само по себе снижение случаев необоснованного применения санкций против законопослушных субъектов (каковое является следствием предлагаемой нами модели) обладает абсолютной ценностью.

Таким образом, предлагаемые методы выявления организаций, причастных к легализации преступных доходов, вкупе с предлагаемыми институциональными изменениями (которые будут описаны ниже в работе) позволяют достичь одновременно двух целей. Во-первых, при новой системе выявления организаций, проводящих сомнительные операции, случаи необоснованного ущемления экономических прав законопослушных агентов станут относительно редки (поскольку предлагаемая нами статистическая модель очень хорошо отсеивает из списка «подозреваемых» те фирмы, которые обладают признаками добросовестного экономического субъекта). Во-вторых, модель практически так же хорошо работает и в обратную сторону: большая часть организаций, причастных к проведению сомнительных операций, хорошо ею улавливается.

Таким образом, в целях выстраивания единой политики в сфере противодействия легализации преступных доходов, до сведения кредитных организаций следует довести перечень характеристик организаций (составленный на основании анализа субъектов, причастных к отмыванию доходов, полученных от преступной деятельности) с разъяснением данных характеристик, которые необходимо учесть при разработке правил внутреннего контроля (см. табл. 4). 


\section{Таблица 4. Список характеристик}

\begin{tabular}{|c|c|}
\hline Характеристика организации & Раскрытие характеристики \\
\hline Отраслевая принадлежность фирмы & $\begin{array}{l}\text { Корректное использование всех нижеприведённых критериев } \\
\text { невозможно без изначального представления о том, какой именно } \\
\text { экономической деятельности занимается анализируемый субъект. } \\
\text { Например, для определения того, является ли объём уплачиваемо- } \\
\text { го фирмой НДС, достаточным, необходимо учесть её отраслевую } \\
\text { принадлежность. Существуют виды деятельности, не облагаемые } \\
\text { НДС; далее, в разных отраслях доля добавленной стоимости в ито- } \\
\text { говой цене может очень сильно различаться (так, в сфере торговли } \\
\text { она всегда меньше, чем в сфере производства) - а значит, и уро- } \\
\text { вень НДС по отношению к обороту будет существенно различаться }\end{array}$ \\
\hline Величина уставного капитала фирмы & $\begin{array}{l}\text { Несмотря на то, что низкий уровень УК является чрезвычайно рас- } \\
\text { пространённым явлением в российских экономических реалиях, } \\
\text { статистический анализ показал, что у фирм, занимающихся прове- } \\
\text { дением сомнительной деятельности, минимальный УК встречается } \\
\text { ещё чаще, чем у прочих }\end{array}$ \\
\hline $\begin{array}{l}\text { Наличие у фирмы запасов в активной } \\
\text { части баланса (при наличии потребно- } \\
\text { сти в таковых исходя из специфики её } \\
\text { основной деятельности, указанной в } \\
\text { соответствии с ОКВЭД) }\end{array}$ & $\begin{array}{l}\text { Данный критерий связан непосредственно с логикой экономи- } \\
\text { ческой деятельности фирмы. Так, организация, занимающаяся } \\
\text { торговой деятельностью и при этом не имеющая запасов, вызывает } \\
\text { закономерные подозрения в фиктивном характере своей деятель- } \\
\text { ности }\end{array}$ \\
\hline $\begin{array}{l}\text { Наличие у фирмы основного капита- } \\
\text { ла (складов и прочего необходимого } \\
\text { капитального имущества) }\end{array}$ & $\begin{array}{l}\text { Данный критерий схож с предыдущим. Он также базируется на } \\
\text { прозрачной экономической логике: например, у фирмы, занимаю- } \\
\text { щейся оптовой торговлей, с необходимостью должны наличество- } \\
\text { вать складские помещения (собственные либо арендованные) }\end{array}$ \\
\hline $\begin{array}{l}\text { Уплата организацией налогов (в пер- } \\
\text { вую очередь НДС) в объёмах, сопоста- } \\
\text { вимых с масштабами её деятельности, } \\
\text { за конкретный отчётный период } \\
\text { (квартал/год) }\end{array}$ & $\begin{array}{l}\text { Уплата налогов, сопоставимых с масштабом выручки и прибыли, } \\
\text { достаточно ясно свидетельствует о том, что организация занимает- } \\
\text { ся осуществлением экономически полезной деятельности, приво- } \\
\text { дящей к созданию добавленной стоимости }\end{array}$ \\
\hline $\begin{array}{l}\text { Наличие у организации достаточного } \\
\text { уровня фонда заработной платы }\end{array}$ & $\begin{array}{l}\text { Фонд заработной платы, позволяющий выплачивать работникам } \\
\text { зарплату в объёме, сопоставимом со средней заработной платы, } \\
\text { ясно указывает на то, что организация занимается осуществлением } \\
\text { реальной хозяйственной деятельностью }\end{array}$ \\
\hline $\begin{array}{l}\text { Наличие организаций, связанных с } \\
\text { данной фирмой через собственников/ } \\
\text { руководителей - в том числе причаст- } \\
\text { ных к совершению противозаконных } \\
\text { экономических операций }\end{array}$ & $\begin{array}{l}\text { Анализ юридических лиц, связанных с данной организацией, по- } \\
\text { зволяет выявить цепочки недобросовестных экономических аген- } \\
\text { тов, вовлечённых в проведение противозаконной деятельности }\end{array}$ \\
\hline Размер штаба сотрудников & $\begin{array}{l}\text { Статистика свидетельствует о том, что фирмы с большим количе- } \\
\text { ством работников реже оказываются вовлечёнными в осуществле- } \\
\text { ние противозаконной деятельности. В основе данного критерия } \\
\text { лежит прозрачная экономическая логика: добросовестные субъек- } \\
\text { ты не захотят подвергать реально функционирующий бизнес, на } \\
\text { построение которого ушло много ресурсов и в который был вложен } \\
\text { значительный капитал, серьёзному риску }\end{array}$ \\
\hline Срок существования фирмы на рынке & $\begin{array}{l}\text { Данный критерий по своей логике схож с предыдущим - за тем } \\
\text { уточнением, что длительность существования фирмы не всег- } \\
\text { да связана с расширением объёмов её деятельности. Напротив, } \\
\text { возможна противоположная ситуация - когда в прошлом успешно } \\
\text { функционировавшая фирма находится на грани банкротства, и её } \\
\text { могут использовать для осуществления сомнительных операций. } \\
\text { По этой причине указанный критерий необходимо использовать в } \\
\text { сочетании с другими }\end{array}$ \\
\hline
\end{tabular}




\section{Библиографический список}

1. Лавроненко Р.А. Статья: Актуальные проблемы противодействия легализации преступных доходов в банковской сфере // «Безопасность бизнеса». 2018. № 2.

2. Лащинина Е.А. «Антиотмывочное» законодательство и аудитор: информировать(,) нельзя(,) молчать () // «Электронный журнал «Финансовые и бухгалтерские консультации». 2019. № 1 .

3. Газета «Коммерсантъ» № 105 от 20.06.2003

4. Публичный отчет Росфинмониторинга: национальная система оценки рисков легализации (отмывания) преступных доходов 